more common' than the red kangaroo. Western grey kangaroos are still abundant in the park, as Cheal has shown. Similarly, the red kangaroo was indeed 'very rare' in Victoria, and has remained so in the park. The records of the Blandowski expedition thus do not support Cheal's contention that the abundance of large kangaroos has increased within Hattah-Kulkyne National Park in historic times.

Graeme Coulson, The University of Melboume, Department of Zoology, Parkuille, Victoria 3052, Australia.

David Cheal was invited to reply to Graeme Coulson's letter and a complex debate ensued. In summary, he wishes to make the following points. Firstly, the records from the Blandowski expedition are too anecdotal to establish pre-European population levels of kangaroos so he did not attempt to use them in this way. Secondly, since the earliest reliable population surveys, carried out by the National Parks Service and the Commonwealth Scientific and Industrial Research Organization, numbers have certainly increased to be among the highest densities ever recorded outside captivity. Thirdly, preEuropean populations of the western grey kangaroo Macropus fuliginosus were apparently higher in the region containing Hattah-Kulkyne National Park than populations of either of the other kangaroos, the eastern grey $M$. giganteus and the red M. rufus. Finally, the crux of his article, and of the park rehabilitation programme, is the fact that the current kangaroo population levels are having a detrimental impact, threatening other species and entire ecosystems. The historical levels are interesting, though indeterminate, but are not open to management.

\section{The survival of the black rhino}

I have recently returned from Zimbabwe where I visited the remote Chizarira National Park and was able to camp and walk and to observe black rhino still relatively numerous in the park. The Warden has recently done a stint with the Zimbabwe National Parks' anti-poaching teams operating particularly in the Lower Zambezi area around Mana Pools, and gave me a vivid account of the battle to save the black rhino in its last stronghold in Africa. I also obtained details of this campaign in discussion with the National Parks and Wildlife Chief Warden in Harare.

It appears that poaching of rhino in the Zambezi Valley is being carried out by highly organized gangs operating across the river from Zambia. They have already killed 200 animals out of an estimated population of 750 in the Mana Pools area. The gangs consist of the same people who have reduced the black rhino population of Zambia's Luangwa Valley from 3000 in the mid1970 s to a mere 200 now.

The National Parks Department in Zimbabwe is fighting back (literally). A total of 22 poachers have been killed by National Parks anti-poaching units, which are currently being strengthened with extra teams. In their operations National Parks have the help of the police Support Unit, a helicopter donated by the World Wildlife Fund and dramatically improved communications thanks to sophisticated radios donated by SAVE (the Foundation to Save African Endangered Wild Life) in the United States. Apart from the co-ordinated government actions to defeat the poachers, there is vital substantial support from organizations and the public within Zimbabwe.

Zimbabwe is doing all that it can, but needs all the help and encouragement it can get from outside. The rest of the world, and especially neighbouring countries, must help to eliminate the underlying problems, namely the demand for rhino horn and the failure to stop the traffic that continues due to some high-level corruption and insufficient awareness and determination on the world's part to end it.

Jonathan Lawley, Flat 5, 56 Nightingale Lane, London SW12 $8 N Y, U K$. 